\title{
Forecasting GDP Per Capita In Bangladesh: Using Arima
}

\section{Model}

\author{
Liton Chandra Voumik, and Dilruba Yesmin Smrity
}

\begin{abstract}
GDP per capita is one of the key indicators of the economic health of any country. It is often used by academicians and decision-makers to plan public and private policies. The work aims to forecast the real per capita GDP in Bangladesh. Using yearly data for Bangladesh from 1972 to 2019, the study analyzes future GDP per capita using the ARIMA technique. The ADF, PP, and KPSS tests showed that the appropriate model to forecast Bangladeshi GDP per capita is ARIMA $(0,2,1)$. Finally, we applied in our paper the ARIMA model $(0,2,1)$ to forecast the GDP per capita of Bangladesh for the next decade. The future GDP per capita shows that living standards in Bangladesh will continue. Indeed, Bangladesh's economy is growing, and other poor countries must learn from Bangladesh's experiences. The study offers policy prescriptions to help policymakers for Bangladesh on how to maintain, preserve, and promote sustainable growth in Bangladesh.
\end{abstract}

Index Terms - GDP per capita, ARIMA Modeling, forecasting, Bangladesh.

\section{INTRODUCTION}

Bangladesh is one of the world's most overpopulated countries, located in South Asia. Bangladesh covers $1,47,570$ square kilometers of land. The current population is about 180 million, exhibiting a high population density of 1265 inhabitants per square kilometer. As a result, Bangladesh's economy has since 80 's decade been experiencing robust, resilient, and sustained GDP growth in the South Asian region averaging over $6 \%$ annually.

Including government purchases, personal consumption, government and private inventories, and the trade balance (differences between exports and imports) GDP represent the market value of all goods and services produced by a country. The production approach, the expenditure approach, and the income approach these popular 3 ways are applied to measure the GDP. The topic for GDP per capita has become the most concerned amongst macroeconomic variables. The figure of GDP per capita is regarded as an important index for assessing national economic health, according to Ning et al [1]. How well the present economy is performing GDP per capita is key indicators in this matter.

Therefore, to get a specific idea of the future trend of any economy accurate prediction of GDP per capita is very necessary. ARIMA model is the main focus of this research

Published on September 26, 2020.

Liton Chandra Voumik, Department of Economics,

Noakhali Science and Technology University, Bangladesh.

(corresponding e-mail: litonvoumik@gmail.com)

Dilruba Yesmin Smrity, Department of Economics,

Noakhali Science and Technology University. to predict the Bangladeshi GDP per capita. The paper is divided into several sections. Literature reviews are included in section 1. Section 2 presents several tests and statistical analysis. In section 3, several tests were applied to get the best ARIMA model and presented Bangladeshi GDP for the next decade. Finally, the last section offers the forecasting figures and conclusion for our study.

\section{LITERATURE REVIEWS}

Box and Jenkins [2] methodology is very popular in the forecasting issue and has been used extensively by many researchers to highlight the base GDP, GDP growth, or per capita GDP.

Applying the ARIMA $(1,2,2)$ with 6 decades of data, Maity and Chatterjee [3] examine the forecasting of GDP growth rate for India. In their findings, the predicted values follow an upward trend for the subsequent years.

Shahini and Haderi [4] examine GDP forecasting for Albania using quarterly data from the first quarter of 2003 until the second quarter of 2013. ARIMA and VAR these two models they applied for forecasting purposes.

Choosing an ARIMA $(1,1,0)$ model, Zakai [5] examines forecasting of GDP for Pakistan using quarterly data during the period 1953- 2012. He shows that Pakistan's GDP would be increasing for the next twelve years.

Using the ARIMA technique Dritsaki [6] found out that the ARIMA $(1,1,1)$ model was the optimal model and investigated real GDP in Greece from 1980 until 2013.

Wabomba et al [7] analyzed GDP using ARIMA models with an annual data set during the period 1960 to 2012 in Kenya. Their findings show that the ARIMA $(2,2,2)$ was the best for modeling the GDP in Kenya.

The reviewed studies indicate that the most prominent approach to analyzing GDP is the Box-Jenkins ARIMA technique, thus the paper will adopt this approach to achieve its goals

\section{OBJECTIVE Of THE STUdY}

To identify the best ARIMA model for forecasting GDP per capita in Bangladesh.

\section{DATA SOURCE}

An annual per capita GDP data for the period of 1972 to 2019 were obtained from annual reports of world development indicators (WDIs). The data file consists of 48 years of GDP per capita (USD). 


\section{METHODOLOGY}

To better understand the time-series data or forecast future data economists apply the ARIMA model. Requiring 30 to 40 observations to build an ARIMA model and forecast short term data.

There are three sections in the ARIMA (p,d,q) models. All sections are identically important.

1. AR (p) or autoregressive orders $\mathrm{p}$ can be articulated as:

$X_{t}=c+\beta_{1} X_{t-1}+\beta_{2} X_{t-2}+\cdots+\beta p X_{t-p}+\varepsilon_{t} ; t=1,2, \ldots 3,4, \ldots T$,

When a time series is regressed on past values from the same data, it is an AR model. So, the AR model predicts future trends based on the previous trends. In this equation $\varepsilon t$ is the error.

2. On the other hand, MA (q) or moving-average process of orders q expressed as:

$$
X_{t}=\varepsilon_{t}-\varnothing_{1} \varepsilon_{t-1}-\varnothing_{2} \varepsilon_{t-2}-\cdots-\varnothing_{q} \varepsilon_{t-q}
$$

Past errors are the basic part of this model. Forecasting short or long term trends, MA is a very helpful and easy technique. If anyone has 30 to 40 observations, he can apply a 3-year, 4-year, or 5-year moving average.

3. ARMA model

ARMA model is the blend of both AR and MA. $p$ and $q$ both are an important part of this model.

$$
X t=c+\beta_{1} X_{t-1}+\cdots+\beta_{p} X_{t-p}+\varepsilon t-\varnothing_{1} \varepsilon_{t-1}-\cdots-\varnothing_{q} \varepsilon_{t-q}
$$

\section{ARIMA Models}

The ARMA model needs to extend to make it nonstationary series by allowing the differencing of the data series resulting in ARIMA models. ARIMA model is the combination of the aforementioned models and the general non-seasonal model is known as ARIMA (p, d, q): wherewith three parameters are here: the orders of autoregressive are $\mathrm{p}$, the degree of difference is $\mathrm{d}$, and $\mathrm{q}$ is the order of moving-average. For example, if $X t$ is nonstationary series, we must take one or more times differences so that $\Delta X t$ behaves stationary, then the ARIMA (p, d, q) model becomes:

$$
\Delta X_{t}=c+\beta_{1} \Delta X_{t-1}+\cdots+\beta p \Delta X_{t-p}+\varepsilon t-\varnothing_{1} \varepsilon_{t-1}-\cdots-\varnothing_{q} \varepsilon_{t-q}
$$

where $\Delta X t=X t-X t-1$. If $\mathrm{p}=\mathrm{q}=0$ in equation (4), then the model looks ARIMA $(0, \mathrm{~d}, 0)$ which is a classified random walk model.

\section{GRAPHS, TABLES, AND FIGURES}

Level Data

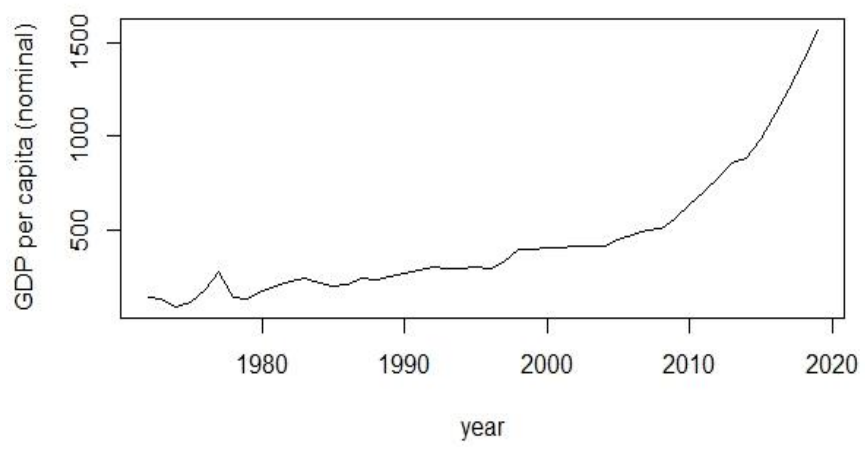

Fig. 1. The upward curve of GDP growth rates in Bangladesh throughout 1972-2019. Source: Compiled from data.

Figure 1 shows the per capita GDP since 1972 to 2019. The line is smoothly upward until 1995. After 2010 the line is dramatically upward.

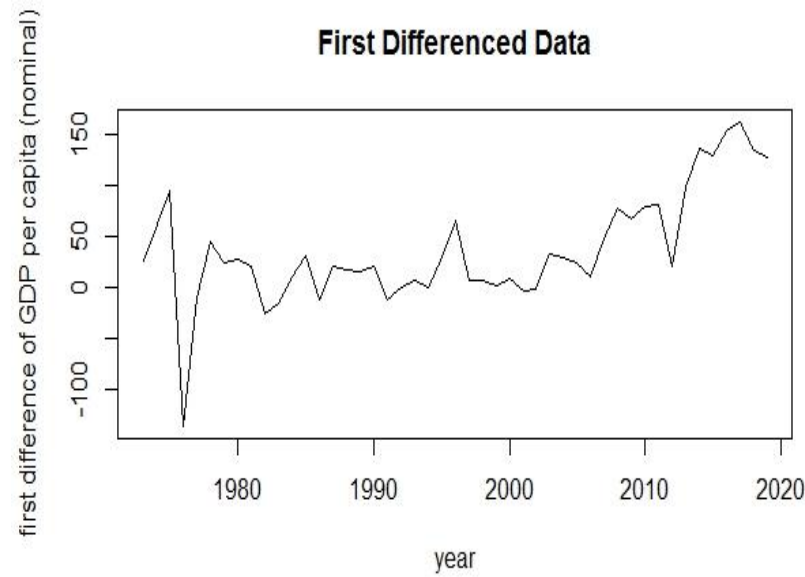

Fig. 2. First-order differencing. Source: Compiled from data.

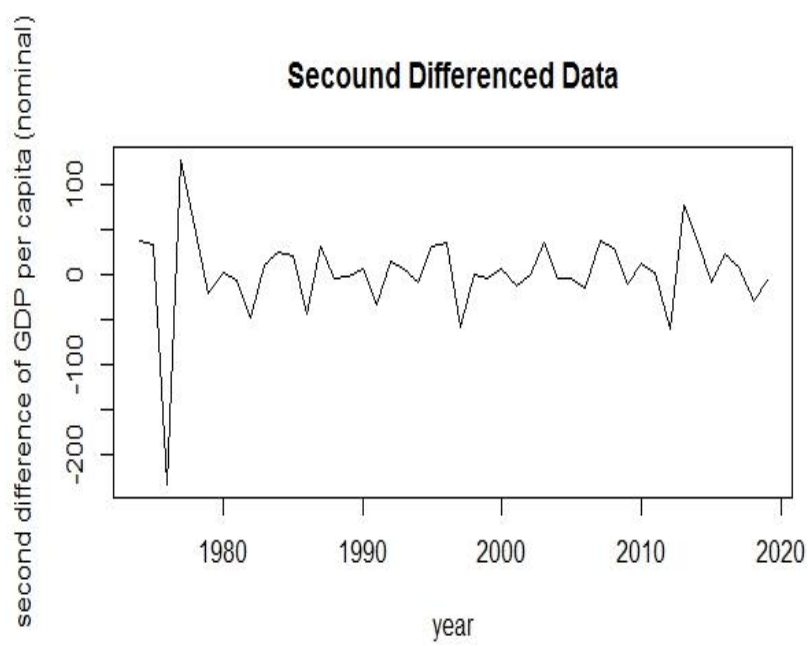

Figure 3. Second-order differencing. Source: Compiled from data.

Figures 2 and 3 show the first and second differences in the data set. We need differencing the data to make it stationary. 


\section{A. Finding the best ARIMA model (ADF test)}

$>$ fit1 <- auto.arima(GDP per capita data, trace=TRUE, test="adf", ic="aic")

TABLE 1: SEVERAL ARIMA MODELS AND AIC VALUES BASED ON

\begin{tabular}{|c|c|}
\hline \multicolumn{2}{|c|}{ ADFTEST } \\
\hline $\operatorname{ARIMA}(2,2,2)$ & 479.9956 \\
\hline $\operatorname{ARIMA}(0,2,0)$ & 488.6174 \\
\hline ARIMA $(1,2,0)$ & 485.1308 \\
\hline ARIMA $(0,2,1)$ & 476.467 \\
\hline ARIMA $(1,2,1)$ & 478.2201 \\
\hline ARIMA $(0,2,2)$ & 477.97 \\
\hline ARIMA $(1,2,2)$ & 478.9326 \\
\hline
\end{tabular}

Best model: ARIMA $(\mathbf{0 , 2 , 1 )}$

>summary(fit1)

Series: GDP per capita data

$\operatorname{ARIMA}(0,2,1)$

Coefficients:

ma1

$-0.6587$

s.e. 0.1014

sigma $^{\wedge} 2$ estimated as 1707: $\log$ likelihood $=-236.23$

$\mathrm{AIC}=476.47 \quad \mathrm{AIC}=476.75 \quad \mathrm{BIC}=480.12$

Training set error measures:

ME RMSE MAE MPE MAPE MASE ACF1

Training set $6.156243 \quad 40.00912 \quad 25.76545 \quad-0.7508707$ 8.4867990 .5572040 .03306447

>jarque.bera.test(fit1\$residuals)

JarqueBera Test

data: fit 1 \$residuals

$\mathrm{X}$-squared $=359.8, \mathrm{df}=2, \mathrm{p}$-value $<2.2 \mathrm{e}-16$

>Box.test(fit1\$residuals,lag=10, type="Ljung-Box")

Box-Ljung test

data: fit1\$residuals

$\mathrm{X}$-squared $=6.6401, \mathrm{df}=10, \mathrm{p}$-value $=0.7589$

B. Finding the best ARIMA model (PP test)

$>$ fit2<-auto.arima(GDP per capita data, trace=TRUE, test="pp", ic="aic")

TABLE 2: SEVERAL ARIMA MODELS AND AIC VALUES BASED ON PP TEST

\begin{tabular}{|c|c|}
\hline ARIMA(2,2,2) & 479.9956 \\
\hline $\operatorname{ARIMA}(0,2,0)$ & 488.6174 \\
\hline $\operatorname{ARIMA}(1,2,0)$ & 485.1308 \\
\hline ARIMA $(0,2,1)$ & 476.467 \\
\hline ARIMA $(1,2,1)$ & 478.2201 \\
\hline ARIMA $(0,2,2)$ & 477.97 \\
\hline ARIMA $(1,2,2)$ & 478.9326 \\
\hline
\end{tabular}

Best model: ARIMA (0,2,1)

>summary(fit2)

Series: GDP per capita data

$\operatorname{ARIMA}(0,2,1)$

Coefficients:

ma1

$-0.6587$

s.e. 0.1014

sigma $^{\wedge} 2$ estimated as 1707: $\log$ likelihood=-236.23

$\mathrm{AIC}=476.47 \quad \mathrm{AICc}=476.75 \quad \mathrm{BIC}=480.12$

Training set error measures:

ME RMSE MAE MPE MAPE MASE

ACF1

Training set $6.156243 \quad 40.00912 \quad 25.76545-0.7508707$

8.4867990 .5572040 .03306447

> jarque.bera.test(fit2\$residuals)

JarqueBera Test

data: fit 2 residuals

$\mathrm{X}$-squared $=359.8, \mathrm{df}=2, \mathrm{p}$-value $<2.2 \mathrm{e}-16$

>Box.test(fit2\$residuals,lag=10, type="Ljung-Box")

Box-Ljung test

data: fit $2 \$$ residuals

$\mathrm{X}$-squared $=6.6401, \mathrm{df}=10, \mathrm{p}$-value $=0.7589$

C. Finding the best ARIMA model (KPSS test)

$>$ fit3 <- auto.arima(GDP per capita data, trace=TRUE, test="kpss", ic="aic")

TABLE 3: SEVERAL ARIMA MODELS AND AIC VALUES BASED ON KPSS

\begin{tabular}{|c|c|}
\hline \multicolumn{2}{|c|}{ TEST } \\
\hline $\operatorname{ARIMA}(2,2,2)$ & 479.9956 \\
\hline $\operatorname{ARIMA}(0,2,0)$ & 488.6174 \\
\hline ARIMA(1,2,0) & 485.1308 \\
\hline ARIMA(0,2,1) & 476.467 \\
\hline ARIMA(1,2,1) & 478.2201 \\
\hline ARIMA(0,2,2) & 477.97 \\
\hline ARIMA(1,2,2) & 478.9326 \\
\hline
\end{tabular}

\section{Best model: ARIMA $(0,2,1)$}

>summary(fit3)

Series: GDP per capita data

$\operatorname{ARIMA}(0,2,1)$

Coefficients:

ma1

$$
-0.6587
$$

s.e. 0.1014

sigma $^{\wedge} 2$ estimated as 1707: $\log$ likelihood $=-236.23$

$\mathrm{AIC}=476.47 \quad \mathrm{AICc}=476.75 \quad \mathrm{BIC}=480.12$

Training set error measures: 
ME RMSE MAE MPE MAPE MASE ACF1

Training set $6.156243 \quad 40.00912 \quad 25.76545 \quad-0.7508707$ 8.4867990 .5572040 .03306447

$>$ jarque.bera.test(fit3\$residuals)

JarqueBera Test

data: fit 3 \$residuals

$\mathrm{X}$-squared $=359.8, \mathrm{df}=2, \mathrm{p}$-value $<2.2 \mathrm{e}-16$

>Box.test(fit3\$residuals,lag=10, type="Ljung-Box")

Box-Ljung test

data: fit3\$residuals

$\mathrm{X}$-squared $=6.6401, \mathrm{df}=10, \mathrm{p}$-value $=0.7589$

Table 1 to 3 shows several models of ARIMA and AIC values. Three different tables show the sets of ARIMA from three popular unit root tests. Now we are going to forecast GDP per capita for the next decade.

$>$ forecasted.data3=forecast(fit3, $\mathrm{h}=10) \quad \# \quad$ fit $\quad$ an $\operatorname{ARIMA}(0,2,1)$ model

$>$ forecasted.data 3

TABLE 4: SAMPLE FORECASTING BASED ON ARIMA(0,2,1) FOR THE SUBSEQUENTLY 10 YEARS

\begin{tabular}{|c|c|c|c|c|c|}
\hline Year & $\begin{array}{c}\text { Point } \\
\text { Forecast }\end{array}$ & Lo 80 & Hi 80 & Lo 95 & Hi 95 \\
\hline 2020 & 1959.786 & 1906.831 & 2012.742 & 1878.798 & 2040.774 \\
\hline 2021 & 2092.573 & 2003.977 & 2152.168 & 1957.077 & 2228.068 \\
\hline 2022 & 2225.359 & 2099.708 & 2351.009 & 2033.193 & 2417.525 \\
\hline 2023 & 2358.145 & 2192.997 & 2523.294 & 2105.572 & 2610.718 \\
\hline 2024 & 2490.932 & 2283.663 & 2698.200 & 2173.941 & 2807.922 \\
\hline 2025 & 2623.718 & 2371.725 & 2875.711 & 2238.328 & 3009.107 \\
\hline 2026 & 2756.504 & 2457.260 & 3055.748 & 2298.850 & 3214.159 \\
\hline 2027 & 2889.290 & 2540.358 & 3238.223 & 2355.644 & 3422.937 \\
\hline 2028 & 3022.077 & 2621.111 & 3423.043 & 2408.852 & 3635.302 \\
\hline 2029 & 3154.863 & 2699.604 & 3610.122 & 2458.605 & 3851.121 \\
\hline
\end{tabular}

Table 4 consists of the projected per capita GDP for the next decade using the ARIMA $(0,2,1)$ model. The third to sixth columns are lower and upper limits of the forecasted growth during the years 2020-2029. There is an expected smooth increase of GDP per capita in Bangladesh.

\section{Forecasts from ARIMA(0,2,1)}

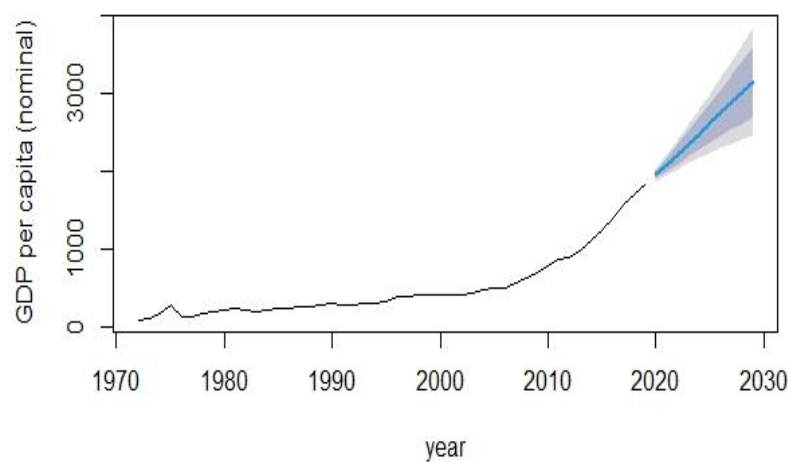

Fig. 4. GDP growth forecasting. Source: Compiled from data.
Forecasts from ARIMA $(0,2,1)$

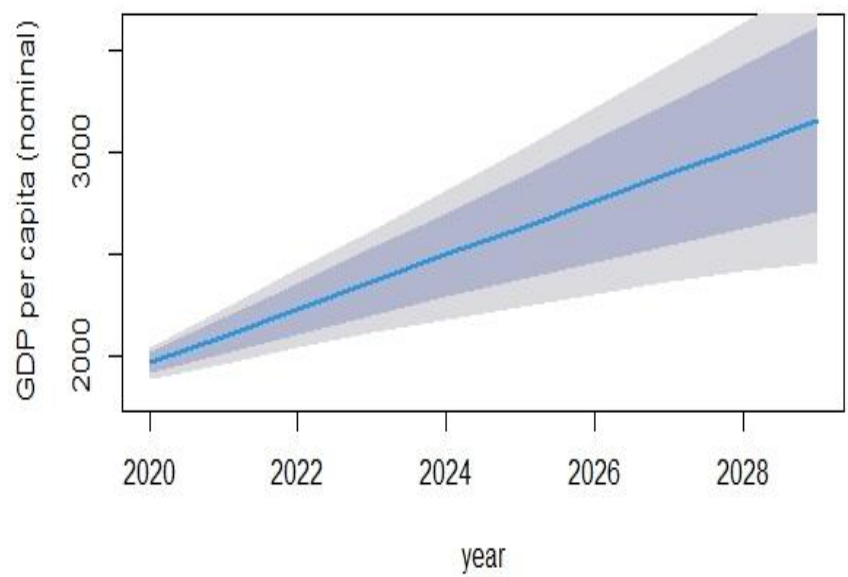

Fig. 5. Growth forecasting with upper and lower bounds. Source: Compiled from data.

Figures 4 and 5 attempts to forecast the GDP per capita in Bangladesh for the next decade. In figure 5, the upper and lower bound are also included.

\section{CONCLUSION}

In this paper, we tried to forecast the GDP per capita in Bangladesh for the next decade with a suitable ARIMA model. The corresponding several tests and checks helped in choosing the appropriate $\mathrm{p}, \mathrm{d}$, and $\mathrm{q}$ for the data series. An ARIMA $(0,2,1)$ model was created and the best model through the data used. Estimating this model, we found that the real GDP per capita is expected to rise in the next decade. If the growth rate will be continuing and smooth the Bangladeshi GDP per capita will be 2623.718 USD in 2025 and 3154.863 USD in 2029. These findings of this research will be supportive for the academicians to know about future GDP per capita and policymakers to originate developmentrelated strategies and effective policies. Furthermore, the findings will also help the managers, entrepreneurs, or business executives to take decisions concerned with the extension of the existing business or implementing new ideas.

\section{REFERENCES}

[1] Ning, W., Kuan-jiang, B. and Zhi-fa, Y. (2010), Analysis and forecast of Shaanxi GDP based on the ARIMA Model, Asian Agricultural Research, Vol. 2 No. 1, pp. 34-41.

[2] Box, G. E. P. \& Jenkins G. M. (1976). Time series analysis. Forecasting and control. Holden-Day, San Francisco.

[3] Maity, B., \&ChatterjeeB. (2012). Forecasting GDP growth rates of India: An empirical study. International Journal of Economics and Management Sciences, 1(9), 52-58

[4] Shahini, L. \& Haderi S. (2013). Short term Albanian GDP forecast: One quarter to one year ahead. European Scientific Journal, 9(34), 198-208

[5] Zakai, M. (2014). A time series modeling on GDP of Pakistan. Journal of Contemporary Issues in Business Research,3(4), 200-210.

[6] Dritsaki, C (2015). Forecasting real GDP rate through econometric models: an empirical study from Greece, Journal of International Business and Economics, 3 (1): 13 - 19.

[7] Wabomba, M. S., Mutwiri, M. P., \& Mungai, F (2016). Modeling and forecasting Kenyan GDP using Autoregressive Integrated Moving Average (ARIMA) models, Science Publishing Group - Science Journal of Applied Mathematics and Statistics, 4 (2): 64 - 73. 


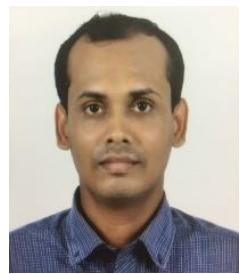

Liton Chandra Voumik earned his bachelor and master's degree from University of Chittagong, Bangladesh. He also completed his master's and MPhil from Florida International University and Middle Tennessee State University, USA.

In 2018, he joined at Department of Economics,

Noakhali Science and Technology University as a faculty member.

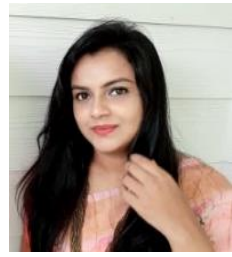

Dilruba Yesmin Smrity earned his bachelor and master's degree from University of Dhaka, Bangladesh

In 2018, she joined at Department of Economics, Noakhali Science and Technology University as a faculty member. 